Cómo citar este artículo: Acle-Mena, R. S., Santos-Díaz, J. Y., \& Herrera-López, B. (2020). La gastronomía tradicional como atractivo turístico de la ciudad de puebla, México. Rev.investig.desarro.innov., 10 (2), 237-248.

\title{
La gastronomía tradicional como atractivo turístico de la ciudad de Puebla, México
}

\section{Traditional gastronomy as a tourist attraction in the city of Puebla, Mexico}

\author{
Ramón Sebastián Acle-Mena' \\ Jessica Yazmín Santos-Díaz ${ }^{2}$ \\ Beatriz Herrera-López ${ }^{3}$
}

Recibido: agosto 27 de 2019

Aceptado: diciembre 19 de 2019

\section{Resumen}

Este artículo busca determinar la relación de la gastronomía tradicional como atractivo turístico de la ciudad de Puebla, México. La investigación se realizó bajo un enfoque turístico-mercadológico de tipo mixto, con cortes correlacional y transversal. La hipótesis general fue de tipo correlacional, así: la gastronomía tradicional incide fuertemente en la ciudad de Puebla como atractivo detonante turístico. La información se recolectó a través de un cuestionario de 19 ítems, evaluados con una escala Likert de 5 puntos. La muestra fue de 383 turistas, que visitaron los restaurantes de comida típica durante la Semana Santa de 2019. Los resultados indican que las variables de calidad y promoción, tienen una correlación alta; mientras que las variables de infraestructura y significado, presentan una correlación moderada; siendo la variable de atención y entretenimiento, la única que presenta una correlación baja. Se concluye que la gastronomía tradicional sí es un detonante de la actividad turística en la ciudad de Puebla. Además, para mejorar su impacto, los encargados del sector deberían mejorar los aspectos relacionados con la atención y el entretenimiento, para lograr una mejor experiencia de los visitantes.

Palabras clave: atractivo turístico, gastronomía tradicional, productos étnicos, Puebla.

\begin{abstract}
This article seeks to determine the relationship of the traditional gastronomy as a tourist attraction of the city of Puebla, Mexico. This research was made under a mixed type: touristic and marketing approach with transversal and correlational analyses. The type of the general hypothesis was correlational; therefore, the traditional gastronomy strongly influences in Puebla City as a trigger for tourism. The information was obtained through a survey with 19 items rated with a 5-point Likert scale. The sampling was 383 tourists, those who visited typical food restaurants during Easter week of 2019. The results indicate that the quality and promotion variables have a high correlation while the infrastructure and meaning variables have a moderate correlation, being the attention and entertainment variable the only one presenting a low correlation. It was concluded that the traditional gastronomy is indeed a trigger of the touristic activity in Puebla City. Furthermore, to improve its impact, those in charge of this sector should improve the related aspects with attention and entertainment to achieve a better experience for the visitors.
\end{abstract}

Keywords: tourist atracttion, traditional food, ethnic products, Puebla.

1 Licenciado en Administración de Empresas, Doctor en Administración Gerencial, Benemérita Universidad Autónoma de Puebla, Puebla, México. E-mail: raclemx@yahoo.com.mx. ORCID: 0000-0002-7313-3723

2 Licenciada en Administración Turística, Benemérita Universidad Autónoma de Puebla, Puebla, México. E-mail: jessyaazmin@gmail.com ORCID: 0000-0002-3654-1904

3 Licenciada en Turismo, Doctora en Gestión de Turismo Regional Sustentable, Benemérita Universidad Autónoma de Puebla, Puebla, México. E-mail: beatrizherreralopez@gmail.com. ORCID: 0000-0003-1741-0164 


\section{Introducción}

La presente investigación se refiere al tema de la gastronomía como un atractivo detonante de la ciudad de Puebla, México. La gastronomía, si bien es el reflejo de un colectivo social (Leal-Londoño, 2011), también puede llegar a ser un referente turístico. Esto debido a las características identitarias que posee cada comunidad, y aunque este quizá no llegue a ser su atractivo principal, se considera pieza importante para complementar la oferta turística que ofrece un destino (Acle-Mena, Villalobos-Abrego \& Herrera-López, 2016). Actualmente, el turismo gastronómico es considerado factor clave del desarrollo de una comunidad, brindando oportunidades de empleo, crecimiento económico y mejora de infraestructura, entre otros (Di Clemente, Hernández-Mogollón \& López-Guzmán, 2014). En este sentido, se considera de gran importancia detectar las cualidades y potencialidades de la gastronomía de un sitio como agente de atracción de flujos turísticos, para gestionarlo de manera adecuada.

Existen diversos estudios que indican la importancia del arte culinario, como parte del turismo de manera inevitable, donde se dan a conocer los beneficios de la gastronomía como un atractivo turístico de un lugar, que trae consigo beneficios en la modificación del espacio, en los ámbitos: social, cultural, económico y ambiental (Mascarenhas-Tramontin \& Gândara-Gonçalves, 2010; Naranjo-Arango, Naranjo-Africano \& LeonesViana, 2018; Mazón, Hurtado \& Colmenares, 2014); sin embargo, en el caso de la ciudad de Puebla, son pocos los estudios que determinen la relación de la gastronomía tradicional como un atractivo detonante turístico. Lo anterior a pesar que la gastronomía poblana es parte importante del legado gastronómico de México, el cual fue declarado por la Organización de las Naciones Unidas para la Educación, la Ciencia y la Cultura (UNESCO), como patrimonio cultural en el año 2010 (UNESCO, 2010).
El presente estudio se realizó durante el período vacacional del 12 al 20 de abril de 2019, bajo un enfoque turístico-mercadológico, siendo de principal interés conocer cómo la gastronomía tradicional incide en la ciudad de Puebla como atractivo detonante turístico. Para ello se diseñó una metodología mixta, bajo un enfoque cualitativo-cuantitativo, que permitió correlacionar las variables del estudio. Los resultados obtenidos servirán de referencia para que los sectores turístico y restaurantero, creen nuevas estrategias adecuadas a Puebla, como destino turístico gastronómico.

\section{Marco teórico y metodología}

\subsection{Atractivo turístico}

La Organización Mundial del Turismo, OMT (2008), estableció una definición para el turismo, explicándolo como: "fenómeno social, cultural y económico relacionado con el movimiento de las personas a lugares que se encuentran fuera de su lugar de residencia habitual, por motivos personales o de negocios/profesionales". Actualmente, el turismo es considerado como uno de los sectores culturales y económicos más importantes que un país puede poseer. Aspectos como los atractivos turísticos -naturales o culturales- son los que definen y motivan a una persona a su desplazamiento a diversos destinos turísticos, para su adquisición y/o uso recreacional directo (Navarro, 2015; SECTUR, 2019).

Hoy en día existen países que han sabido hacer buen uso de la diversidad que les brinda de manera bondadosa la naturaleza y su herencia cultural, causando la llegada de grandes cantidades de turistas. Según la OMT, en el año 2017, México se posicionó como uno de los países con mayor recepción de turistas, junto con: Francia, España, EU, China, Italia, Reino Unido, Turquía, Alemania y Tailandia (De la Rosa, 2018). Esto gracias a la privilegiada posición geográfica, que ofrece una variedad de atractivos turísticos, desde el clásico turismo de sol y playa en varios centros 
vacacionales localizados en ambas costas del país, hasta el turismo arqueológico, que testimonia el devenir de avanzadas civilizaciones precolombinas (Benseny, 2007). Asimismo, la UNESCO (2017), dio a conocer que México cuenta con 34 sitios inscritos en la lista de Patrimonio Mundial, de los cuales: 6 bienes son naturales, 27 son culturales y 1 mixto, mencionando que es el país de América Latina con más reconocimientos en el listado y el sexto a nivel mundial, por detrás de: Italia, España, China, Francia y Alemania.

México, como destino turístico, destaca en la parte cultural, sobresaliendo en: distinguidas celebraciones (día de muertos, día de la Guadalupana, la fiesta de la Guelaguetza, la feria de San Marcos, entre otras); el legado arqueológico presente en diversos sitios del país, así como en la amplia y diversa gastronomía que motiva a los visitantes a dirigirse a sitios específicos (Ceballos, 2018).

El arte culinario como fuente de atractivo de flujos turísticos, es de gran importancia al ser un elemento casi obligado durante una visita a un lugar ajeno al del turista. Ejemplo de ello es Perú, cuyo turismo entra por la cocina, recibiendo 59\% de extranjeros motivados a conocer la tierra andina por su gastronomía (Farje, 2019). La gastronomía de un sitio se convierte en un elemento clave para el posible retorno de un turista, con el objetivo específico de deleitar platillos que plasman la cultura de un lugar.

En el caso de México, las ciudades más visitadas por motivo de gastronomía, son: Ciudad de México, Riviera Maya, Oaxaca, Guanajuato, Michoacán y Puebla, entre otras (Rodríguez, 2018). Puebla, como joya turística cultural por excelencia, es reconocida debido a su diversidad gastronómica y profunda importancia histórica, por lo cual se posiciona hoy en día como uno de los destinos turísticos obligados en una visita por la República Mexicana (EL UNIVERSAL, 2018).

\subsection{Ciudad de Puebla}

Puebla es uno de los destinos más cosmopolitas de México, que combina la grandeza de un pasado histórico con la modernidad de una ciudad única en su tipo (Travel, 2019). Está situada al este de la ciudad de México, en un valle en el centro oriente del territorio mexicano rodeado de cuatro importantes volcanes; Popocatépetl, Iztaccíhuatl, Malinche y Citlaltépetl. Fue fundada el 16 de abril de 1531, en el valle de Cuetlaxcoapan, y concebida como modelo urbanístico en su época (Domínguez-Silva, 2005).

Su capital, también conocida como "relicario de América", es una de las ciudades coloniales más bellas de México, resultado de la gran cantidad de monumentos concentrados en su centro histórico, obteniendo la mención como "patrimonio cultural de la humanidad" por la UNESCO el 11 de diciembre de 1987. Luego se le otorgó la mención de "Memoria del mundo", dentro del patrimonio documental en el 2005, por albergar la biblioteca Palafoxiana, primera biblioteca pública de América y testimonio inalterado del legado europeo en América (UNESCO, 2005). Recientemente, fue nombrada "Ciudad Creativa del Diseño", en la categoría de diseño, porque fomenta el potencial creativo, social y económico de las colectividades locales para promover la diversidad cultural (UNESCO, 2016). Dentro de los atractivos turísticos de Puebla, destacan: sus iglesias, museos, sitios de recreación, zonas arqueológicas y gastronomía.

En 2018, Puebla se posicionó dentro de los principales destinos de México, junto con: Ciudad de México, los Cabos, Guadalajara, Cancún, Monterrey, Acapulco y Querétaro. En ese año, el estado de Puebla recibió 6.227.000 turistas, siendo el destino más importante la ciudad de Puebla, con 14.958.319 visitantes (Rodríguez, 2018). Lo anterior como resultado de la promoción de los atractivos naturales, culturales, arqueológicos y gastronómicos del estado (SECTUR, 2019a). 
El turismo gastronómico en Puebla ha ido tomando importancia en los últimos años, siendo uno de los factores turísticos referentes de la ciudad. El vicepresidente de Turismo y Cultura de la Cámara de Comercio (CANACO), informó que en marzo de 2018, 30 de cada 100 turistas escogieron Puebla como destino para degustar comida tradicional, como: chalupas, cemitas, mole poblano, chiles en nogada, mole de caderas, dulces típicos y memelas (Lozano, 2018). Puebla cuenta con 395 establecimientos, de los cuales 44 ofrecen bebidas alcohólicas y 351 ofrecen alimentos variados. Veinte restaurantes destacan por ofrecer comida tradicional poblana, entre ellos: la casita poblana, el mural de los poblanos, la casona de la china poblana, casa real poblana, la casa del mendrugo, la fonda de santa Clara y el anafre rojo (INEGI, 2019).

\subsection{Gastronomía tradicional poblana}

La gastronomía es una de las disciplinas más importantes para el hombre del siglo XXI, ya que se le reconoce su carácter esencial para la salud de las personas, su contribución a la estética y a los procesos culturales que forman parte de una identidad comunitaria que permiten fortalecer los vínculos sociales, considerándose también una herramienta para el desarrollo local (Ansón, 2016). La gastronomía típica que se asocia a cada contexto, es parte del patrimonio de las sociedades, un trazo de su identidad que se refleja a través del cultivo, los productos y platos típicos, o las formas de servir y consumir, que son tan nuestras pero a la vez tan diferentes en contextos culturales extraños, simplemente por no ser propias o no estar habituadas a ellas (Fusté-Forné, 2016). La gastronomía típica se configura como un elemento clave en el turismo y su promoción, así como en la competitividad de los destinos turísticos. Ella pretende dar respuesta a un tipo de viajero cada vez más identificado con la búsqueda de lo autóctono, y de los elementos culturales de la zona geográfica que visita (López-Guzmán \& Margarida, 2011).
El turismo gastronómico, es aquel en el cual la motivación principal de desplazamiento del turista es la alimentación y las prácticas gastronómicas de una determinada localidad, brindándole una experiencia del lugar visitado a través de un platillo (Ruschmann, 1997). Este tipo de turismo puede producir efectos positivos, como: complementa la oferta turística local, atraer nuevas inversiones a la localidad donde se desarrolla, contribuir al aumento de la generación de empleo y a la recaudación de impuestos, difundir la cultura local, aumentar la circulación de conocimiento técnico y contribuir a la formación de una imagen positiva para la región, rescatando o preservando la cultura local a través de las actividades turísticas (Mascarenhas-Tramontin, 2005).

Los turistas ven a la gastronomía como la posibilidad de conocer mejor la cultura de un lugar. No es solo el acto de probar la comida que atrae turistas por motivos culturales, sino la posibilidad de conocer los rituales y hábitos asociados a la gastronomía de un pueblo, la posibilidad de visitar museos sobre esta temática o aprender a preparar platos de un determinado lugar. Quien viaja para aumentar su conocimiento sobre la gastronomía de un lugar, o para aprender a preparar un plato, está viajando debido a una motivación gastronómica cultural (Oliveira, 2011).

En el caso de Mealhada, Portugal, Oliveira (2011), evidencia una profunda relación entre la gastronomía y el turismo, incluso excesiva ya que casi todo el turismo del municipio depende de este recurso. El autor considera importante un plan estratégico para el turismo, bajo la perspectiva del desarrollo sostenible, que contemple apostar a otros productos y que procure mejorar la oferta en el área de la gastronomía, en especial en lo que respecta a: la certificación, calificación de recursos humanos y compromiso de los empresarios del área de los restaurantes, para brindarle una buena experiencia al visitante.

Torres-Rodríguez, Álvarez-Ojeda y Véléz-Cedeño (2017), muestran que tras la identificación de los 
platillos principales de Pedernales, Ecuador, se pueden detectar las potencialidades del patrimonio gastronómico para convertirse en uno de los atractivos turísticos, que motiven la realización de viajes hacia el destino Pedernales. Los autores concluyen que la gastronomía es un vehículo de la identidad y autenticidad de un territorio, obteniendo de ella ventajas competitivas para el desarrollo del turismo y para el crecimiento de las comunidades acogidas. Hasta 2017, los países que destacaban a nivel mundial por su gastronomía eran: Líbano, Vietnam, Japón, Perú, Italia, India, China, Francia, España y México (Alonso, 2017).

La cocina tradicional mexicana es un modelo cultural completo, que comprende: actividades agrarias, prácticas rituales, conocimientos prácticos antiguos, técnicas culinarias y costumbres y modos de comportamiento comunitarios ancestrales (UNESCO, 2010). Los elementos básicos de esta cocina, son: el maíz, los fríjoles y el chile. Igualmente, se apoya en productos originarios de su tierra y presume una gran creatividad en sus cocineros, mismos que a lo largo de los siglos han ido perfeccionando esta gastronomía. Lo anterior llevó a que en el 2010, la gastronomía mexicana fuera considerada como Patrimonio Inmaterial de la Humanidad por la UNESCO.

La gastronomía poblana es producto del mestizaje, que devino con la Conquista de México por parte de los españoles, siendo una de las más representativas de la República Mexicana. Sus platillos conjugan los ingredientes prehispánicos, las especias de Asia y África, los procedimientos de España y otros países europeos (Hernández, 2017). Puebla contó, desde sus orígenes, con varios monasterios de distintas órdenes religiosas. Entre ellos destacaron los conventos de las monjas angelopolitanas, que a parte de las tareas piadosas, también se dedicaban al arte de la cocina, donde se destacaron por la creación de todo tipo de platillos y repostería de la época colonial (Moreno \& Coromoto, 2011). Las monjas, durante su tiempo libre, se dedicaban al bordado y a la cocina. Su esmero en la elaboración de los platillos era para impresionar a los nobles y sus invitados. Es así como nace la mesa poblana, expresada en la tradición y las costumbres de la ciudad de Puebla de los Ángeles, en la que además de los platillos, existe un ambiente singular, en el que no pueden faltar los objetos de barro y madera, así como las elegantes vajillas de talavera (Kiosko, 2004).

Esta ciudad vivió el temprano desarrollo de una bien sustentada industria alimentaria y crecimiento del comercio, con: vendajes, botillerías, tocinerías y tiendas de abarrotes. En el siglo XVIII, se crean los platillos con sabores dulces, los chiles en nogada, moles y salsas (pipián, adobo, chirmoles, clemoles, machamanteles y moles de moles). Igualmente, en este siglo aparecen dulces, como: tortitas de santa Clara, camotes poblanos, jamoncillos, mazapanes, suspiros de monja, cocadas, alfajores, dulces de huevo y buñuelos, atribuidos al convento de Santa Clara. En el siglo XIX, la ciudad de Puebla hizo una importante contribución a la gastronomía, con la producción de recetarios (Acle-Mena \& Montiel, 2018).

Puebla es el único lugar de México en donde los platillos tienen fecha de nacimiento, ligados a acontecimientos históricos que los identifican. Además de ello, tiene una importante variedad gastronómica que la hace atractiva para el turista a la hora de planear un viaje, por lo que los platillos típicos se convierten en un referente de este destino (Riestra, 2005).

Los platillos típicos más reconocidos, son: el mole poblano, chile en nogada, chalupas, cemitas, pipían, molotes, tortitas de Santa Clara, camotes y mole de caderas. Asimismo, algunos generan movimientos turísticos dentro de la ciudad, de acuerdo a las fechas del año, como los chiles en nogada en el mes de agosto, y el mole de caderas en el mes de octubre (Fuentes-Juárez \& Barragán, 2019). 


\subsection{Metodología}

La investigación fue realizada bajo un enfoque turístico-mercadológico de tipo mixto, con cortes correlacional y transversal, utilizando los métodos: deductivo, analítico y sintético (Ramírez-Hernández, Cruz-Jiménez \& Vargas-Martínez, 2018). El objetivo principal fue determinar la relación de la gastronomía tradicional, como atractivo detonante turístico de la ciudad de Puebla. La hipótesis general fue de tipo correlacional, quedando redactada de la siguiente manera: la gastronomía tradicional incide fuertemente en la ciudad de Puebla como atractivo detonante turístico.

Los instrumentos de recolección de información fueron la encuesta y la entrevista, utilizando un cuestionario de 19 ítems, evaluados a través de una escala Likert de 5 puntos $(1=$ totalmente en desacuerdo, a $5=$ totalmente de acuerdo).

El modelo del constructo se realizó de acuerdo con Guzmán-Sala y Mayo-Castro (2016), donde se detectaron las tres variables más importantes que los atractivos requieren en el desarrollo de la oferta turística, a saber: i) condiciones de la infraestructura -muestra instalaciones públicas que unen partes de la ciudad y proporcionan los servicios básicos que la ciudad necesita para su funcionamiento-; ii) atención y entretenimiento -conjunto de servicios que se prestan al turista para informarle y orientarle durante su viaje o su estancia en destino, así como la gama de actividades que incrementen la satisfacción del turista-; y iii) promoción -estrategias para que el turista regrese a la ciudad, con el motivo de deleitar platillos típicos-. Además, se agregaron dos variables importantes para el desarrollo de un atractivo turístico: i) calidad -mide el grado de interés de los turistas hacia el conjunto de las características inherentes de un producto o servicio turístico, que deberán cumplir con sus necesidades y expectativas (Catellucci, 2009)-; y ii) significado -muestra la importancia de un atractivo en función del área territorial donde es conocido o divulgado-.
Es decir, el modelo para la presente investigación quedó conformado por estas cinco variables: condiciones de la infraestructura, orientación turística, promoción, calidad y significado. Estas no solo evalúan el lugar donde se consumen, sino también la experiencia gastronómica que se llevan los turistas, de acuerdo con las propiedades y particularidades de los platillos tradicionales poblanos. El orden de los ítems en el cuestionario, fue el siguiente: del 1 al 3 para la variable de calidad, del 4 al 6 para significado, del 7 al 10 para la variable infraestructura, del 11 al 13 para atención y entretenimiento, del 14 al 16 para la variable promoción, y del 17 al 19 para la variable dependiente. Para la parte cualitativa y descriptiva, se realizaron 7 preguntas de corte demográfico.

Los ítems se validaron para su fiabilidad bajo el Coeficiente de Alfa de Cronbach, obteniendo un valor de .73, por lo que se consideró aceptable para su aplicación (Cervantes, 2005). Se tomó como unidad de análisis, a los restaurantes del centro histórico y sus alrededores, y como sujetos de estudio a los turistas que visitaron los establecimientos de comida tradicional en la ciudad de Puebla, durante el período vacacional de semana Santa (14 al 20 de abril de 2019), siendo una temporada alta en materia de turismo.

El tamaño de la muestra se determinó a partir de una búsqueda en el Directorio Estadístico Nacional de Unidades Económicas (DENUE), del Instituto Nacional de Estadística, Geografía e Informática (INGEI). Se encontraron registrados 396 restaurantes, fondas, cafeterías y bares, según su padrón al 2019. De este universo, se seleccionó como población solo a los restaurantes que tuvieran la característica de ofrecer comida tradicional poblana, llegando a encontrarse 69 establecimientos, de los cuales se seleccionaron los más representativos en cuanto a calidad, variedad de platillos poblanos, difusión pero sobre todo a la atracción de turistas que reciben para deleitar, específicamente, platillos típicos de la ciudad. Finalmente, se escogieron los 11 siguientes: la fonda de Santa Clara, Anafre rojo, la casa de los muñecos, casa Reyna, el mural de los poblanos, casa del mendrugo, la casona de la china poblana, 
el moyuelo, casa real poblana, el mercado de sabores y fonda que chula es Puebla (Beteta, 2018; Tripadvisor, 2019).

En la población del estudio se consideró a los visitantes de la ciudad de Puebla, durante el mes de abril de 2018, contemplando el centro histórico y la ocupación hotelera, llegando a 274.489 turistas, según cifras de la Secretaría de Turismo (DATATUR, 2019). De esta cantidad, solo se tomó la proporción correspondiente a una semana, que representa el período vacacional objeto de estudio, ajustándose a 68.622 turistas. La muestra se calculó con la siguiente expresión: considerando un $95 \%$ de confiabilidad, $5 \%$ de margen de error, $50 \%$ de probabilidad a favor y $50 \%$ de probabilidad en contra, llegando a un resultado de 383 turistas.
La recolección de información se efectuó con 11 encuestadores, alumnos de la Facultad de Administración, de la Benemérita Universidad Autónoma de Puebla (BUAP). Cada uno aplicó 5 encuestas diarias, a través de una entrevista cara a cara, durante siete días (12 al 20 de abril), en el horario de 1 a 5 pm, en los 11 restaurantes antes mencionados.

Para relacionar la variable dependiente con las independientes, se hizo uso de la técnica estadística del coeficiente de correlación de Pearson, el cual se corrió a través del programa estadístico Minitab. En la tabla 1 se muestra la interpretación y significado de la escala de correlación de Pearson, base para la interpretación de los resultados del estudio.

Tabla 1. Escala de la correlación de Pearson y su interpretación (Goviden, 1985).

\begin{tabular}{ll}
\hline Valor de correlación & Interpretación \\
\hline 0 & Correlación Nula \\
0,01 a 0,19 & Correlación positiva muy baja \\
0,2 a 0,39 & Correlación positiva baja \\
0,4 a 0.69 & Correlación positiva moderada \\
0,7 a 0,89 & Correlación positiva alta \\
0,9 a 0,99 & Correlación positiva muy alta \\
1 & Correlación positiva grande y perfecta \\
\hline
\end{tabular}

\section{Resultados y discusión}

A continuación se describen las variables demográficas cualitativas, a saber: edad, género, ocupación, estado civil, procedencia, número de acompañantes y días de estancia, para los 383 turistas encuestados.

En cuanto a la edad: el $60 \%$ de las personas encuestadas oscila entre 41 y 60 años; el $27 \%$ está entre 20 y 40 años; mientras que el $13 \%$ son mayores de 61 años. Asimismo, el 53\% de los visitantes fueron mujeres y el $47 \%$ hombres. En cuanto a la ocupación: el $43 \%$ de los turistas son empleados, $34 \%$ son empresarios, $13 \%$ jubilados, $8 \%$ estudiantes, mientras que el $2 \%$ tienen otras ocupaciones.
Para el estado civil: el $63 \%$ de los encuestados son casados, $31 \%$ son solteros y $6 \%$ señaló la opción otro.

Igualmente, el $92 \%$ de estos visitantes son de origen nacional, mientras que el $8 \%$ son extranjeros. El $43 \%$ viajan acompañados de 3 a 5 personas, 35\% con dos personas, $17 \%$ con una persona, y el $5 \%$ van con un grupo de más de 5 personas. Además, el $61 \%$ reporta una estancia de 1 a 3 días, el 29\% de 4 a 6 días, y 10\% permanecieron 6 días o más.

La interpretación de resultados y la comprobación de las hipótesis de trabajo: calidad, significado, infraestructura, atención y entretenimiento y promoción, se aprecian en la tabla 2. 
Tabla 2. Comprobación de hipótesis.

\begin{tabular}{ll}
\hline Hipótesis & Coef. Co \\
\hline H1. CALIDAD: determinada por valor intrínseco, estado de conser- & 0.75. \\
vación y entorno. & \\
& \\
H2. SIGNIFICADO: determinada por local, provincial, nacional e & 0.69. \\
internacional. &
\end{tabular}
internacional.

H3. INFRAESTRUCTURA: determinada por infraestructura restau- 0.57 . rantera, estacionamientos, señalética y accesibilidad.

H4. ATENCIÓN Y ENTRETENIMIENTO: determinada por informa- 0.36 . ción y orientación turística, visitas y recorridos gastronómicos, servicios de entretenimiento y asociación con otros atractivos.

H5. PROMOCIÓN: determinada por acciones estatales, acciones por empresarios del sector restaurantero, ferias y eventos gastronómicos.

0.71

En la tabla 2, se observa que las variables de calidad y promoción, tienen una correlación alta; mientras que las variables de infraestructura y significado, presentan una correlación moderada; siendo la variable de atención y entretenimiento, la única que presenta una correlación baja. Estos valores comprueban la hipótesis del estudio, es decir, que la gastronomía tradicional sí es un detonante de la actividad turística en la ciudad de Puebla; sin embargo, para incrementar el impacto de la gastronomía, será necesario mejorar los elementos asociados a la atención y entretenimiento, como: la información y orientación turística, visitas y recorridos gastronómicos, servicios de entretenimiento, así como la asociación con otros atractivos.

Los resultados anteriores coinciden con Oliveira (2011), quien obtuvo evidencia positiva de la relación entre la gastronomía y el turismo, sugiriendo la necesidad de apostar por la creación de productos complementarios, que puedan mejorar la experiencia en el área gastronómica. Igualmente, se coincide con Torres-Rodríguez et al. (2017), donde muestran que la gastronomía puede llegar a ser un atractivo turístico, a través de la motivación de los turistas para desplazarse a un lugar específico, siendo la competitividad para el desarrollo del turismo un resultado de ello. En este sentido, se reafirma que la gastronomía tradicional poblana, por: su historia, riqueza, variedad y conservación, entre otras características, incide fuertemente en la ciudad como un detonante turístico.

\section{Conclusiones}

El modelo de evaluación de atractivos turísticos propuesto en el estudio, conformado por 5 variables: calidad, significado, infraestructura, atención, y entretenimiento y promoción, permitió comprobar la hipótesis de la investigación. Esto 
debido a que los coeficientes de correlación de Pearson para las variables estudiadas, fueron moderados o altos, salvo para la atención y entretenimiento, que tuvo una correlación baja.

En otras palabras, se demostró que la gastronomía tradicional de la ciudad de Puebla, es un atractivo turístico detonante de la actividad turística de la ciudad. Además, para mejorar su impacto, los encargados del sector deberían mejorar los aspectos relacionados con la atención y entretenimiento, para lograr una mejor experiencia de los visitantes. Es decir, a pesar que la gastronomía inevitablemente forma parte de la actividad turística, esta puede llegar a ser un motivo primario de desplazamiento, por lo que se deben realizar estudios adicionales, que permitan comprender las demandas y exigencias de los turistas.

Finalmente, el estudio proporciona una metodología que puede ser utilizada para futuras investigaciones, ya sea en la ciudad de Puebla o en otros lugares, que impliquen otros platillos y en diferentes temporadas del año. Esto redundará en un mejor conocimiento del impaccto de la gastronomía en la actividad turística, permitiendo que autoridades y empresarios realicen una administración más eficiente del sector.

\section{Referencias}

Acle-Mena, R. S., \& Montiel, A. V. (2018). Influencia de la gastronomía mexicana en el consumo étnico en España. Revista interamericana de ambiente y turismo, 14 (2), 89-101. doi: http://dx.doi. org/10.4067/S0718-235X2018000200089

Acle-Mena, R. S., Villalobos-Abrego, C., \& Herrera-López, B. (2016). Reposicionamiento del Barrio del Artista para aumentar su valor cultural-artístico en Puebla, México. Revista de Investigación, Desarrollo e Innovación, 6 (2), 109-116. Doi: http:// doi.org/10.19053/20278306.4601
Alonso, J. (8 de septiembre de 2017). Los 10 países con la mejor comida del mundo. Travel Report. Recuperado de: https:// ww w.travelreport.mx/gastronomia/ los-10-paises-con-la-mejor-comida-del-mundo/

Ansón, R. (2016). Cultura y gastronomía. Cuenta y Razón del Pensamiento Actual, 143. Recuperado de: http://www.cuentayrazon.org/revista/pdf/143/ Num143_003.pdf

Benseny, G. (2007). El turismo en México. Apreciaciones sobre el turismo en espacio litoral. Aportes y Transferencias, 11 (2), 13-34. Recuperado de: http:// nulan.mdp.edu.ar/332/

Beteta, M. (24 de febrero de 2018). Los cinco mejores restaurantes de Puebla. El Universal. Recuperado de: https://www.eluniversal.com.mx/ destinos/los-5-mejores-restaurantes-de-puebla

Catellucci. (2009). La calidad y los servicios en destinos turísticos maduros. Aportes y Transferencias, 13 (2), 29-44. Recuperado de: https://www. redalyc.org/pdf/276/27621943003.pdf

Ceballos, F. (15 de abril de 2018). Expansión. Recuperado de: https://expansion.mx/ opinion/2018/04/11/opinion-por-que-la-culturaes-el-motor-del-turismo-en-mexico

Cervantes, V. H. (2005). Interpretaciones del coeficiente alpha de Cronbach. Avances en Medición, 3 (1), 9-28. Recuperado de: https://www.researchgate.net/publication/259392074_Interpretaciones_del_coeficiente_alpha_de_Cronbach

DATATUR. (2019). Reportes. Secretaría de Turismo. Recuperado de: https://www.datatur.sectur.gob. $\mathrm{mx}: 81 /$ Reportes/Menu.aspx

De la Rosa, A. (27 de agosto de 2018). México, el sexto país más visitado del mundo: OMT. El Economista. Recuperado de: https:// www.eleconomista.com.mx/empresas/ 
Mexico-el-sexto-pais-mas-visitado-del-mundo-OMT-20180827-0042.html

Di Clemente, E., Hernández-Mogollón, J., \& López-Guzmán, T. (2014). La gastronomía como patrimonio cultural y motor del desarrollo turístico. Un análisis DAFO para Extremadura. Tejuelo: Didáctica de la Lengua y la Literatura, 9, 817-833. Recuperado de: https://dialnet.unirioja.es/servlet/ articulo?codigo $=5385975$

Domínguez-Silva, P. (2005). Vinculación de la ciudad histórico-turística de Puebla a través de itinerarios culturales. Economía, Sociedad y Territorio, 5 (19), 595-615. doi: http://dx.doi. org/10.22136/est002005295

EI UNIVERSAL (16 de agosto de 2018). Reconocen a Puebla como un destino turístico amable. Recuperado de: https://www.eluniversal.com.mx/ estados/reconocen-puebla-como-un-destino-turistico-amable

Farje, O. (2 de agosto de 2019). Perú: 59\% de turistas tiene en la gastronomía su principal motivación para visitar el país. Agencia Andina. Recuperado de: https://andina.pe/agencia/noticia-peru-59-turistas-tiene-la-gastronomia-su-principal-motivacion-para-visitar-pais-677196.aspx

Fuentes-Juárez, N., \& Barragán, S. (2019). Mole de caderas, una tradición en Tehuacán. Revista Buen viaje. Recuperado de: https://www.revistabuenviaje.com/conocemexico/saboramexico/ mole_de_caderas/mole_caderas.php

Fusté-Forné, F. (2016). Los paisajes de la cultura: la gastronomía y el patrimonio culinario. Dixit, 24 (1), 4-16. doi: https://doi.org/10.22235/d.v0i24.1166

Goviden, L. (1985). Introducción a la Estadística. Colombia: McGraw-Hill.

Guzmán-Sala, A., \& Mayo-Castro, A. (2016). Evaluación de los atractivos turísticos de Tabasco, México.
International Journal of Scientific Management and Tourism, 2 (2), 151-161. Recuperado de: https:// www.researchgate.net/publication/313821648 Evaluacion_de_los_Atractivos_Turisticos_de_ Tabasco

Hernández, J. (2017). Orígenes de la cocina poblana. México: Planeta.

INEGI. (2019). Directorio Estadístico Nacional de Unidades Económicas. Recuperado de: https:// www.inegi.org.mx/app/mapa/denue/

Kiosko. (23 de Mayo de 2004). Tradición culinaria. El siglo de Durango.

Leal-Londoño, M. (2011). La diversificación del destino turístico a través del turismo gastronómico: el caso de Vilanova i la Geltrú (Barcelona). PASOS, 9 (1), 15-24. doi: https://doi.org/10.25145/j. pasos.2011.09.002

Lópéz-Guzmán, T., \& Margarida, M. (2011). Turismo, cultura y gastronomía. Una aproximación a las rutas culinarias . Tourism \& Management Studies, 1 , 915-922. Recuperado de: https://dialnet.unirioja. es/servlet/articulo?codigo $=5018471$

Lozano, G. (19 de marzo de 2018). Gastronomía de Puebla atrae al 30\% de turistas, destaca la Canaco. Puebla, México.

Mascarenhas-Tramontin, R. (2005). Reflexões sobre o turismo gastronômico na perspectiva da sociedade dos sonhos. Recuperado de: https:// www.academia.edu/489722/Reflex\%C3\%B5es_ sobre_o_turismo_gastron\%C3\%B4mico_na_perspectiva_da_sociedade_dos_sonhos

Mascarenhas -Tramontin, R. G., \& Gândara-Gonçalves, J. M. (2010). Producción y transformación territorial. La gastronomía como atractivo turístico. Estudios y Perspectivas en Turismo, 19 (5), 776-791. Recuperado de: https://dialnet.unirioja. es/servlet/articulo?codigo $=3352414$ 
Mazón, T., Hurtado, J., \& Colmenares, M. (2014). El turismo gastronómico en la península lbérica: el caso de Benidorm, España. Revista de Ciencias Sociales de la Universidad Iberoamericana, 9 (18), 73-99. Recuperado de: https://ibero.mx/ iberoforum/18/pdf/ESPANOL/4.\%20MAZON\%20 COLMENARES\%20Y\%20HURTADO\%20VOCES\%20 Y\%20CONTEXTOS\%20NO18.pdf

Moreno, M., \& Coromoto, M. (2011). Turismo y producto turístico. Evolución, conceptos, componentes y clasificación. Visión Gerencia, 1, 135-158. Recuperado de: https://www.redalyc.org/ pdf/4655/465545890011.pdf

Naranjo-Arango, R., Naranjo-Africano, G., \& LeonesViana, A. R. (2018). La gastronomía colombiana. atractivo turístico en crecimiento. Hitos de Ciencias Económicas Administrativas, 24 (68), 103-115. Recuperado de: http://revistas.ujat.mx/index.php/ hitos/article/view/2509/1921

Navarro, D. (2015). Recursos turísticos y atractivos turísticos: conceptualización, clasificación y valoración. Cuadernos de Turismo, 35 (1), 335-357. Recuperado de: https://www.redalyc.org/ pdf/398/39838701014.pdf

Oliveira, S. (2011). La gastronomía como atractivo turístico primario de un destino. Estudios y Perspectivas del Turismo, 20 (3), 738-752. Recuperado de: https://www.redalyc.org/articulo. oa? id=180717583012

Organización Mundial del Turismo, OMT. (2008). Glosario. Recuperado de: http://cf.cdn.unwto.org/ sites/all/files/docpdf/glossarysprev.pdf

Ramírez-Hernández, O. I., Cruz-Jiménez, G., \& Vargas-Martínez, E. E. (2018). Un acercamiento al capital social y al turismo desde el enfoque mixto y mapeo de actores. Antropología Experimental, (18). doi: https://doi.org/10.17561/rae.v0i18.3806
Riestra, M. (2005). El mole poblano y los productos alimenticios mexicanos. Recuperado de: https:// www.cultura.gob.mx/turismocultural/cuadernos/ pdf12/articulo8.pdf

Rodríguez, D. (1 de agosto de 2018). Los destinos de México más visitados por los viajeros. El país. Recuperado de: https://verne.elpais.com/ verne/2018/07/31/mexico/1533000174_214683. html

Ruschmann, D. (1997). Turismo e planejamento sustentável: a proteção do meio ambiente. Papirus Editora.

SECTUR. (15 de enero de 2019). DATATUR. Recuperado de: https://www.datatur.sectur.gob.mx/ SitePages/Glosario.aspx

SECTUR. (2019a). Estadísticas turísticas. Recuperado de: http://culturayturismo.puebla.gob.mx/ estadisticas/estadisticas-turisticas

Torres -Rodríguez, R., Álvarez-Ojeda, V., \& Véléz-Cedeño, J. (2017). La gastronomía como atractivo turístico. Caso Pedernales, Ecuador. Retos turísticos, 16 (1). Recuperado de: http://retos.mes.edu.cu/ index.php/retojs/article/view/253

Travel, P. (2019). Puebla es mi destino. Recuperado de: http://puebla.travel/es/puebla

Tripadvisor. (2019). Restaurantes mexicanos en Puebla. Recuperado de: https://www. tripadvisor.com.mx/Restaurants-g152773c29-Puebla_Central_Mexico_and_Gulf_Coast. html\#EATERY_OVERVIEW_BOX

UNESCO. (2005). Organización de las Naciones Unidas para la Educación, la Ciencia y la Cultura. Recuperado de: http://www.unesco. org/new/es/communication-and-information/ memory-of-the-world/register/full-list-of-registered-heritage/registered-heritage-page-1/ biblioteca-palafoxiana/ 
UNESCO. (2010). La cocina tradicional mexicana, cultura comunitaria, ancestral y viva - El paradigma de Michoacán. Recuperado de: https://ich. unesco.org/es/RL/la-cocina-tradicional-mexicana-cultura-comunitaria-ancestral-y-viva-el-paradigma-de-michoacan-00400

UNESCO. (2016). Puebla, Ciudad Creativa del Diseño para la UNESCO. Recuperado de: http:// www.unesco.org/new/es/media-services/singleview/news/puebla_ciudad_creativa_del_diseno_ para_la_unesco/

UNESCO. (2017). México. Recuperado de: http:// www.unesco.org/new/es/mexico/work-areas/ culture/world-heritage/ 